\title{
Pd-catalysed [3 + 3] annelations in the stereoselective synthesis of indolizidines
}

\author{
Olivier Y. Provoost ${ }^{1}$, Andrew J. Hazelwood ${ }^{2}$ and Joseph P. A. Harrity ${ }^{* 1}$
}

\section{Preliminary Communication}

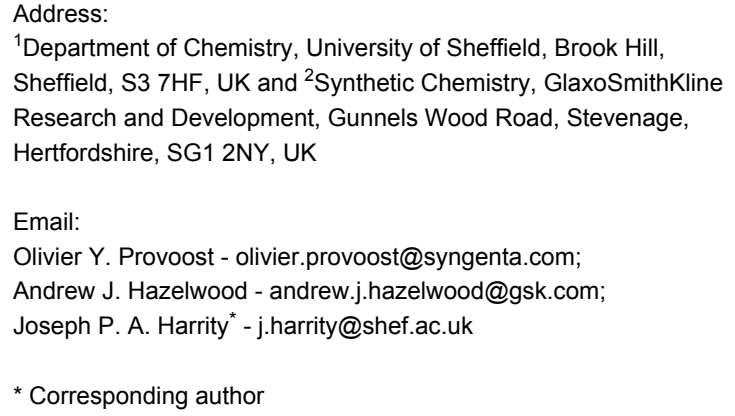

Beilstein Journal of Organic Chemistry 2007, 3, No. 8. doi:10.1186/1860-5397-3-8

Received: 13 September 2006

Accepted: 08 February 2007

Published: 08 February 2007

(C) 2007 Provoost et al; licensee Beilstein-Institut. License and terms: see end of document.

\begin{abstract}
A [3 + 3] annelation of enantiomerically pure aziridine 7 provides the functionalised piperidine 8 that can be elaborated to the indolizidine skeleton in only 4 steps with good stereocontrol.
\end{abstract}

\section{Introduction}

Indolizidine alkaloids represent one of the most structurally diverse classes of natural products and have attracted considerable attention because of their varied biological activity (some examples are illustrated in Scheme 1) [1]. Recent studies in our labs have demonstrated that a range of piperidine alkaloids, [2-6] including quinolizidine based targets, $[7,8]$ can be prepared stereoselectively through the employment of a $[3+3]$ annelation strategy [9]. This approach exploits the commercially available reagent 1 developed by Trost [10] that employs a nucleophilic allylsilane motif in conjunction with an allylic acetate moiety. In an effort to expand our studies to new structural classes, we have turned our attention to the employment of this technique in the synthesis of indolizidines. Specifically, and as outlined in Scheme 1, we envisaged that a key piperidine intermediate 3 could be prepared in enantiomerically pure form and converted into a functionalised indolizidine inter- mediate 4 within a few steps. We wish to report herein our recent progress towards this goal.

Our studies began with the preparation of an appropriate precursor to the desired functionalised piperidine (Scheme 2). Specifically, we prepared an enantiomerically pure silyl protected aziridine 7 using a modification of the route described by Righi and co-workers [11]. Accordingly, tosyl protection of $(R)$-serine 5 followed by esterification and TBDPS-protection provided $\mathbf{6}$ in good overall yield. Ester reduction was carried out conveniently on multigram scale using $\mathrm{LiBH}_{4}$ to give an amino alcohol that was smoothly transformed to aziridine 7 after Mitsunobu condensation.

Having arrived at the key [3+3] annelation step, we decided to employ our standard conditions for the Pd-catalysed reaction. 
Table 1: Investigation of the $[3+3]$ annelation reaction

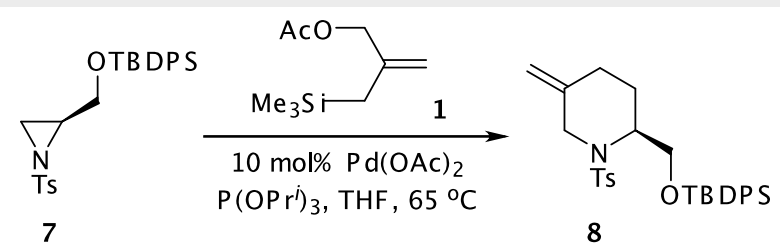

\begin{tabular}{cccc}
\hline Entry & Reductant & mol\% P(O'Pr) & Yield \\
\hline 1 & n BuLi & 60 & $74 \%$ \\
2 & - & 60 & $38 \%$ \\
3 & - & 40 & $25 \%$ \\
4 & - & 80 & $11 \%$
\end{tabular}<smiles>O[C@H]1CN2CCC[C@@H](O)[C@H]2[C@H]1O</smiles>

$(\rightarrow-$ S wainsonine

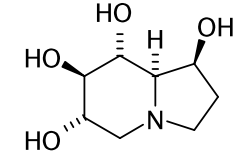

(+)-Castanospermine

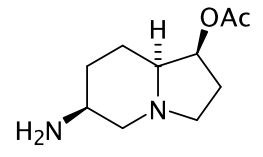

$(-)-$ Slaframine

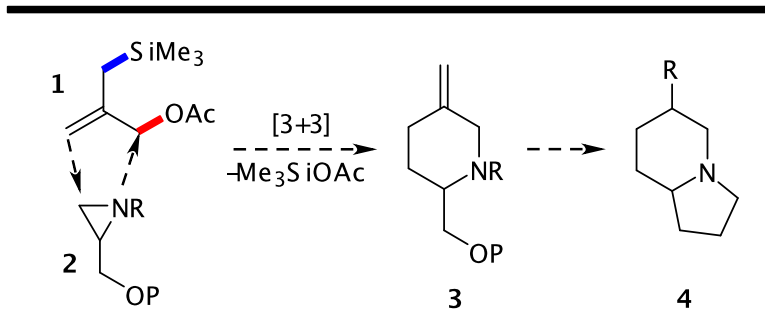

Scheme 1: [3 + 3] Annelation approach to indolizidine skeleta.

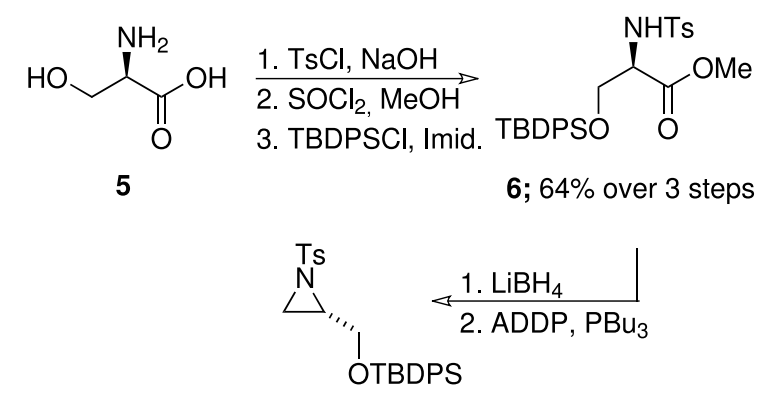

7; $92 \%$ over 2 steps

Scheme 2: Enantiospecific aziridine synthesis (ADDP: 1,1'-(azodicarbonyl)dipiperidine).

Indeed, we were pleased to find that the desired piperidine $\mathbf{8}$ could be furnished in high yield and that this reaction allowed 2-3 $\mathrm{g}$ of material to be made available at this stage (Table 1, Entry 1). Moreover, we took the opportunity to carry out a study into the role of $n$-BuLi in this process. Specifically, Trost described the use of this reagent as a reductant for the generation of low valent Pd required for generation of the intermediate TMM-reagent [12]. However, the ability of phosphite to carry out the reduction of $\operatorname{Pd}(\mathrm{II})$ to $\operatorname{Pd}(0)$ suggested to us that the annelation should proceed equally well in the absence of $n$-BuLi [13]. In an effort to clarify this issue we carried out a study of the $[3+3]$ reaction in the absence of the alkyllithium reagent. As outlined in Table 1, Entries 2-4, the annelation was found to proceed in the absence of $n$-BuLi, however, in all cases the yield of cyclisation product was significantly lower than with catalyst generated by the organolithium reagent. Whilst the underlying reasons for this difference in catalyst activity are unclear at present, we speculate that $n$-BuLi may be responsible for the formation of hitherto uncharacterised phosphine ligands $\mathrm{Bu}_{\mathrm{n}} \mathrm{P}\left(\mathrm{O}^{\mathrm{i}} \mathrm{Pr}\right)_{3-\mathrm{n}}$ that promote the annelation over simple $\mathrm{P}\left(\mathrm{O}^{\mathrm{i}} \mathrm{Pr}\right)_{3}$. Indeed, analogous alkoxide substitution reactions of phosphites have been reported using Grignard reagents [14]. In addition, ${ }^{31} \mathrm{P}$ NMR studies showed that the addition of 1 equivalent of ${ }^{\mathrm{n}} \mathrm{BuLi}$ to $\mathrm{P}\left(\mathrm{OPr}^{\mathrm{i}}\right)_{3}$ gave a mixture of $\mathrm{P}\left(\mathrm{OPr}^{\mathrm{i}}\right)_{3}$ and $\mathrm{PBu}_{3}{ }_{3}$ after 15 minutes (See Supporting Information File 1 for details). Interestingly however, we have found $\mathrm{PBu}_{3}{ }_{3}$ to be inefficient in $[3+3]$ reactions as it appears to promote by-product formation [8]. Studies into the nature of the catalyst in the presence of $n$-BuLi are ongoing.

With the key piperidine 8 in hand, we turned our attention to the assembly of the indolizidine skeleton. Deprotection of the silyl ether proceeded smoothly and the alcohol was oxidised to the corresponding aldehyde 9 under Swern conditions. Addition of the Li-enolate of EtOAc to the crude aldehyde provided the aldol product 10 in high yield and with good diastereocontrol (Scheme 3). Notably, reduction of $9\left(\mathrm{NaBH}_{4}, \mathrm{MeOH}\right)$ followed by formation of the corresponding Mosher's ester showed a single resonance in the ${ }^{19} \mathrm{~F}$ NMR spectrum $(235$ $\mathrm{MHz}, \mathrm{CDCl}_{3}: \delta$-72.0) suggesting that minimal epimerisation had taken place during the oxidation process. 


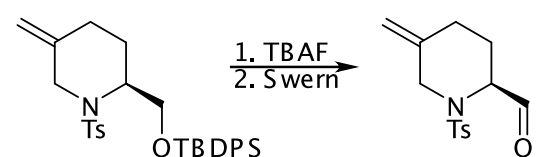

8

9; $86 \%$ over 2 steps<smiles>C=C1CC[C@@H](CC(O)CC(=O)OCC)N(S)C1</smiles>

$10 ; 70 \%$; d.r. $=8: 1$

Scheme 3: Diastereoselective aldol addition

We next decided to investigate the formation of the azabicycle via the deprotection of the Ts-amine moiety followed by cyclisation onto the ester. Previous work in the quinolizidine area had shown that these transformations could be achieved in one-pot by the use of $\mathrm{Mg}$ turnings in methanol at ambient temperature $[7,8]$. Indeed, subjecting $\mathbf{1 0}$ to these conditions provided the desired indolizidine 11, albeit in modest yield. Finally, acetylation of the hydroxyl group provided $\mathbf{1 2}$ and allowed the diastereoisomers to be separated and individually characterised (Scheme 4). Unfortunately however, we were unable to determine the product stereochemistry unequivocally in either case (the ${ }^{1} \mathrm{H}$ NMR data for the minor diastereomer of 12 compares well with a close analogue reported by Knapp and co-workers suggesting that the aldol addition reaction proceeds under Felkin-Anh control [see Supporting Information File 1]).<smiles>C=C1CC[C@H](CC(O)CC(=O)OCC)N(C)C1</smiles>

10
12; $100 \%$; d.r. $=8: 1$

\section{Scheme 4: Indolizidinone formation}

In conclusion, we have shown that functionalised indolizidinone intermediates can be generated through the Pd-catalysed [3+3] annelation of aziridines and Trost's conjunctive allylsilane reagent. We have also found that reduction of the lactam unit of $\mathbf{1 1}$ and acetylation of the hydroxyl group takes place smoothly to provide $\mathbf{1 3}$, demonstrating the potential of these intermediates for the synthesis of slaframine and related indolizidines (Scheme 5).

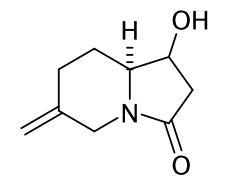

11

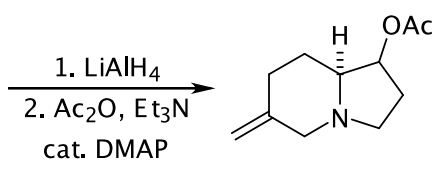

13; $92 \%$ over 2 steps
Scheme 5: Preparation of a functionalised indolizidine.

\section{Supporting Information}

\section{Supporting Information File 1}

Supporting information. Experimental procedures and compound characterisation.

[http://www.beilstein-journals.org/bjoc/content/ supplementary/1860-5397-3-8-S1.doc]

\section{Acknowledgments}

We thank the EPSRC and GSK for studentship funding.

\section{References}

1. Takahata, H.; Momose, T. In The Alkaloids; Cordell, G. A., Ed.; Academic Press: San Diego, 1993; Vol. 44. Chapter 3.

2. Hedley, S. J.; Moran, W. J.; Prenzel, A. H. G. P.; Price, D. A.; Harrity, J. P. A. Synlett 2001, 1596. doi:10.1055/s-2001-17443

3. Hedley, S. J.; Moran, W. J.; Price, D. A.; Harrity, J. P. A. J. Org. Chem. 2003, 68, 4286. doi:10.1021/jo030002c

4. Goodenough, K. M.; Raubo, P.; Harrity, J. P. A. Org. Lett. 2005, 7, 2993. doi:10.1021/ol050965t

5. Provoost, O. Y.; Hedley, S. J.; Hazelwood, A. J.; Harrity, J. P. A. Tetrahedron Lett. 2006, 47, 331. doi:10.1016/j.tetlet.2005.11.015

6. Pattenden, L. C.; Wybrow, R. A. J.; Smith, S. A.; Harrity, J. P. A. Org. Lett. 2006, 8, 3089. doi:10.1021/ol0610789

7. Moran, W. J.; Goodenough, K. M.; Raubo, P.; Harrity, J. P. A. Org. Lett. 2003, 5, 3427. doi:10.1021/ol035156t

8. Goodenough, K. M.; Moran, W. J.; Raubo, P.; Harrity, J. P. A. J. Org. Chem. 2005, 70, 207. doi:10.1021/jo048455k

9. Hsung, R. P.; Kurdyumov, A. V.; Sydorenko, N. Eur. J. Org. Chem. 2005, 23. doi:10.1002/ejoc. 200400567

10. Trost, B. M. Angew. Chem., Int. Ed. Engl. 1986, 25, 1. doi:10.1002/ anie. 198600013

11. Righi, P.; Scardovi, N.; Marotta, E.; ten Holte, P.; Zwanenburg, B. Org. Lett. 2002, 4, 497. doi:10.1021/ol0170152

12. Trost, B. M.; Nanninga, T. N. J. Am. Chem. Soc. 1985, 107, 1293. doi:10.1021/ja00291a032

13. Trost, B. M.; Renaut, P. J. Am. Chem. Soc. 1982, 104, 6668. doi:10.1021/ja00388a032

14. Berlin, K. D.; Austin, T. H.; Stone, K. L. J. Am. Chem. Soc. 1964, 86, 1787. doi:10.1021/ja01063a027 


\section{License and Terms}

This is an Open Access article under the terms of the Creative Commons Attribution License

(http://creativecommons.org/licenses/by/2.0), which permits unrestricted use, distribution, and reproduction in any medium, provided the original work is properly cited.

The license is subject to the Beilstein Journal of Organic Chemistry terms and conditions:

(http://www.beilstein-journals.org/bjoc)

The definitive version of this article is the electronic one which can be found at:

doi:10.1186/1860-5397-3-8 